\title{
The Relationship among TV Violence, Aggression, Anti-Social Behaviors and Parental Mediation
}

\author{
Juliet Dinkha \& Charles Mitchell
}

\author{
American University of Kuwait, Associate Professor of Psychology, jdinkha@auk.edu.kw \\ Independent Researcher, PO Box 3323 Safat Kuwait, 13034, Charlesamitchell@gmail.com
}

\section{Doi:10.5901/mjss.2014.v5n23p1906}

\begin{abstract}
This paper proposes to ascertain whether there is a correlation between parent-child relationships and media consumption in Kuwait, and if so, it will examine the factors that play a role in it such as the parents' education level, marital status, and socioeconomic status (SES). In our research we attempt to find out whether when there is less parental supervision and interaction if this will lead children into consuming more television and whether more television consumption will lead adolescents to assume anti-social behaviors, most notably violent behaviors. We built on the theory of modeling and social learning and the effects on violence, seminally noted in the work by Albert Bandura, and theorized that we would also find correlations with TV consumption and violent behaviors in our sample. We wrote, assembled and circulated a qualitative survey based on the literature review consisting of personal interviews of 120 respondents and asked them about their childhood relationship with TV, violent behavior, and their parents' control of their TV consumption. We reported our results as a narrative based on the responses in our sample. What we found in our results was that a large number of adolescents in Kuwait were exhibiting violent behaviors directly correlated to the amount of violent content they consumed on TV as a child especially when there was little parental control or mediation, this was especially true with the male respondents in our sample.
\end{abstract}

Keywords: violence, Kuwait, TV, modeling theory, social learning theory.

\section{Introduction}

In the last 25 years Kuwait has significantly upgraded its communications infrastructure. Following the Gulf War in 1990, the government embarked on a massive capital improvement of the country's telecommunications. This media revolution was due partly to security as a direct result of the invasion of Iraq and also as a service to an increasingly affluent Kuwaiti population. This modern communications infrastructure endowed Kuwait with a media environment that more closely resembles a European country than it does other emerging economies (Mitchell, Dinkha, Kononova, Rashwan, Matta 2014).

According to the 2013 Press Freedom Index Kuwait is ranked number one for countries in the Middle East with the most open news media environments (Reporters Without Borders 2013). However, despite this rating, state run TV, especially entertainment programming is still highly controlled and censored and so is the most of the mass media available in the country. Books, magazines, TV programming, Internet and almost all foreign media are subject to strict moral regulations (BBC.com 2013). Because of this censorship most of the domestic TV audiences in Kuwait turn to foreign satellite and black market uncensored DVDs as an alternative to filtered state run broadcasting. Only 13 percent of university students surveyed reported to have watched government controlled Kuwait TV, with many more 68 percent reporting they watched foreign channels (Wheeler 2000, Mitchell et al. 2014). Despite the issues with local TV censorship, television consumption is a vital pastime in the country. More than 94 percent of the households in the country have access to satellite television (Mitchell et al. 2014). In a survey conducted at Kuwait University, 73 percent of those polled reported watching TV every day and 95 percent reported that they consumed at least 2.5 hours of TV daily, while 16 percent consumed more than five hours of television in an average day (Wheeler 2000). Because of the recent advent of modern communications in Kuwait in the last 25 years, the impact on the first generation of those who grew up in the contemporary television and information age in the country has created a boon in the research potential on its influence. Our research is twofold, encompassing mass communications and psychology. We specifically explore how parenting behaviors directly affects children's consumption of television and what, if any, heavy TV viewing is having on children in the country. We theorize in our research that heavy television coupled with minimal or neglectful parental behaviors will lead to children developing or modeling anti-social behaviors or attitudes seen on TV. 


\subsection{Literature review}

\subsection{TV consumption, child development, and aggression}

By the time children are 3-years old they are consuming on average of two to three hours of television per day. Children spend more time with the television remote control than they do behind their desks at schools. More than 1000 research studies have examined and drawn correlations between children's TV consumption and violent behaviors, but direct causation has never been established (Black 1995). It is generally believed that TV viewings affects children in four primary ways: 1 . Leading to imitation of what they see 2. Reducing their sensitivity to violent themes and images, 3.Mitigating the effect of other external agents on the moral ramifications of violent behavior and 4 . Creating or increasing arousal. However, many of these studies also posit that there are many other environmental variables and most likely a mix of these variables lead to aggressive behaviors. Children's ages, cognitive ability, and parenting are fundamental to the way each child interprets TV violence. The consensus of the wealth of investigations into the effects of TV violence on children posits that the more hours a child spends consuming TV messages the greater the correlation between TV viewing and aggressive attitudes and behaviors (Black 1995; Murray 2008).

Most of the research into this field has been accumulated in the Western world, with Britain, Canada, and the United States among the primary pioneers. This westernization of the effects of TV and violence leads to a deficit in the body of research in developing nations such as Kuwait. The accumulated data throughout this particular inquiry examines the following questions: Does the relationship between parent/guardian and child affect the child's level of media consumption and the behavior of the child? It is hypothesized that healthy and secure relationships between parent/guardian and child may indicate a stronger sense of attentiveness from parent/guardian and obedience from the child, indicating less TV consumption and pro-social behavior in the child. Meanwhile, weak relationships between parent/guardian and child may indicate lack of attentiveness from parent/guardian and rebellion from the child, indicating more TV consumption and anti-social behavior.

A number of possible factors that may play a role in the correlation between parent-child relationships and TV consumption including the parents' socioeconomic status (SES), education, and social class. In addition, the parent's own television viewing habits and attitudes and knowledge regarding the child's viewing can also be another variable that plays a role in this correlation. A number of theories suggest that the parent's beliefs about the realism of television violence might aggravate or alleviate how television affects the child. Furthermore, whether the parent watches what the child watches might indicate the parent's concern and attitudes about television's effect on his or her children. Moreover, a number of experimental studies suggest that intervention by an adult might moderate the effect TV violence has on the child (Hicks 1968; Huesmann, Lagerspetz, Eron 1984). However, no evidence of such an effect has been reported in a field study. Similarly, it raises the question whether television-viewing habits can be passed on from parent to child. There is some evidence that it is possible (Soneson, 1979; von Feilitzen, 1976), but it does not answer the question regarding the possibility of parents who watch more violence also have children who watch more violence (Huesmann et al., 1984).

The article Imitating Life, Imitating Television: The Effects of Family and Television Models on Children's Moral Reasoning by Marina Krcmar and Edward T. Vieira, Jr. (2005) focuses more on how children's viewing habits and parent-child relationship may affect their acquisition of morality. One example of this is that children imitate certain behaviors either from family or television. According to Krcmar, Vieira, Jr (2005) one of the five keys of good parenting is modeling, since the parents are considered role models for their children's character development. When parents demonstrate positive behaviors in front of their children, the children themselves will be motivated to model the behavior.

However, it's not only parents that children are modeling. Modeling falls under the social learning theory paradigm. The theory asserts that parents, peers, role models, and the mass media acts as an agent of socialization, for which behaviors are imitated. Albert Bandura studied the effects of modeling on pre-school children in his seminal experiment in the 1960's. In his study, videotaped scenarios on televisions were shown to groups of children to gauge their direct effect on the behaviors of the children (Bandura, Ross \& Ross 1961; Dominick 2009). The reactions of the children after viewing the mediated message were also filmed. The objective of the research was to examine the extent and the ways that children model and learn behaviors by observation. Since its publication, Bandura's research has been at the forefront of debate on the effects of violent programming on the anti-social behaviors of children. One six month study, sponsored by American television network CBS sampled more than 1500 school age boys and investigated the relationship between their aggressive behaviors and their television viewing habits. Of the 12 percent (188 boys) who were involved in 10 or more acts of violence over that period, boys who consumed more TV violence had been engaged in the more serious acts of violence (Murray 2008). However, another 1982 study by the US broadcaster NBC published 
in Murray (2008) surmises no direct correlations between television consumption and violence in a large sample of boys. "On the basis of the analyses we carried out to test for such a causal connection there is no evidence that television exposure has a consistently significant effect on subsequent aggressive behavior in the [elementary school] sample of boys" pg 1218. Still, one the longest studies on the topic repudiates the NBC data and concurs with the 1978 CBS investigation. Researchers followed school children for 10 years from the ages of eight to 18. Children were questioned about their viewing habits and favorite shows. Peer ratings were collected to establish their aggressive behaviors and violent content in their favorite programs was also measured across the two time periods. What researchers found was that exposure to early television violence was a factor in producing violent behaviors in later years. Other studies found early onset of aggressive behaviors. Several investigations concluded that violence in cartoons led to increased violence in children's playrooms (Murray 2008).

A wide body of cross sectional surveys over the last 50 years have reached the conclusion that physical aggression is directly correlated to the amount of television a child consumes on TV and in film (Anderson 2003). These surveys have had different methodologies, examined children in across a diverse sample of ages and many have found children and adolescents who were consuming TV images engaging in violent behavior no matter their gender. Some of the research examined, however, noted that aggression was particularly prevalent in children but less so when examined in older children or young adults. The sheer volume of the data seen in a comprehensive meta-analysis of 410 research studies published between 1957 and 1990 find strong correlations between TV consumption of violent images and violent behaviors in children. However, some research still indicates that violent content does still affect older audiences such as teenagers and young adults 19 or older, which leads to conclusion that even in older children -- teens and adults --the effect of TV violence is still tangible. Some studies have even found strong connections between news programming and violence, especially suicide rates, with reports on suicides often times leading to increased likelihood that some viewers may take their own lives ( Anderson 2003).

While the breadth of preceding studies have directly addressed the issue of TV and violence in children and adolescents, as Black (1995) postulates, other socialization agents are factors in how a child interprets and expresses violence, including the relationship between parent and child. A paramount dynamic in the parent-child relationship and its connection with media violence is whether open communication is present in areas of mediating conflicting morals. Ideally, if there is open, honest, and respectful communication between parent and child, then the child will develop coping methods to control moral dilemmas and will additionally empathize with other perspectives on these issues. Accordingly, parent-child communication and control determines how a child would emulate certain behaviors from television, and increases crystallizing of morals (Krcmar et. al 2005).

Consequently, many argue that the parent-child relationship plays an imperative role in whether children model certain behaviors seen on television. Ingunn Hagen (2007) suggests methods for parents and their children to determine how much television a child should consume. Some of the methods used to regulate TV consumption include children seeking parental permission to watch television and specifying how long they can watch TV. The parents' role is to decide how much TV and what programs are appropriate for their children of different ages, or even relegating TV viewing for after their child has finished doing their homework. In essence, the parents' biggest concern mostly pertained to how children use their time. Interestingly, one of the respondents in the study said that asking his parents to video tape his favorite cartoon after his bedtime is how he bypasses this rule. In another case, an 11-year-old subject says that he goes to be at $9 \mathrm{pm}$ and thus could not watch anything after that time. In other cases, parents would divert their children's attention by asking them to play outdoors or to take a break from being in the house. Along this line, another family reported that the reason behind their 'no TV before $6 \mathrm{pm}$ rule' is due to a desire to keep the children busy, since they believe that children should have interests outside of TV viewing for better development of critical thinking and motor skills (Hagen 2007).

Other researchers have also delved into the subject of parental intervention and supervision of TV consumption, specifically looking at the how to help children cope with messages from television advertisements. Some of these proposed methods included implementing more public regulation of advertisements, tuning into more TV programs targeted at children and encouraging parents to become more involved with their children's TV habits (Walsh, Laczniak, \& Carlson, 2000). The authors suggest that parents become more involved by watching TV with their children in order to help them distinguish the differences between a TV program and an advertisement; however, the authors conclude that often times children consume TV without any parental supervision. Correspondingly, there are four types of parenting styles: Neglecting, Indulgent, Authoritarian, and Authoritative, suggesting that the type of parenting style used may have an effect on their children and their TV viewing habits. For instance, neglectful parents do not pay attention to what their children watch on TV since they are not actively involved with their children and are not very restrictive. Indulgent parents (also known as permissive) parents, try to remove as many external restraints to their children's behaviors, as possible, 
while at the same time ensuring their children's wellbeing. They are generally characterized as very involved with their children, and give them their rights and space, but not all the responsibilities that come with being more independent. Unlike indulgent parents, Authoritarian parents tend to be stricter when interacting with their children: expecting children to obey without question and negating two-way communication. Authoritative parents are described as more willing to engage with their children directly and are warm, yet restrictive because they expect their children to act responsibly and to adhere to family rules. However, once the children are older they are allowed more independence and self-expression. (Walsh, Laczniak, \& Carlson, 2000).

\section{Methodology}

A questionnaire consisting of 22-items was assembled based on the literature review (Table. 1). The survey was disseminated to 120 random respondents around Kuwait via face-to -face interviews personal interviews. The respondents were asked to answer the survey based on their experiences with TV, violent behavior and their parents' mediation of their TV consumption until they were 16 years of age. We utilized student assistants to circulate and administer the survey. We surveyed subjects up to the age of 30 as we wanted a clearer recollection of childhood memories with TV and violent behavior, so we found it practical to cap the age of our respondents. Although the survey was face to face, consisting of personal interviews the names of the respondents were not recorded but the standard demographic questions were asked. The survey was initially pre-tested on 30 randomly selected individuals who live in Kuwait. Comments about questions they found irrelevant or could not answer such as violent sports, violent video games played in Kuwait or if it was not culturally understood, were deleted or modified. The pretesting questions allowed us to validate and modify the survey before finally distributing to our sample. We randomly looked for participants between 18 and 30 years of age who could recall the type of TV shows they watched and who could recall how their parents mediated TV viewing. As previously stated, this study aimed to address the correlation between children's TVI media violence viewing habits and its relation to aggressive behaviors in Kuwait. This research also explored the effects of parental mediation of TV consumption on child, adolescent and adult violence.

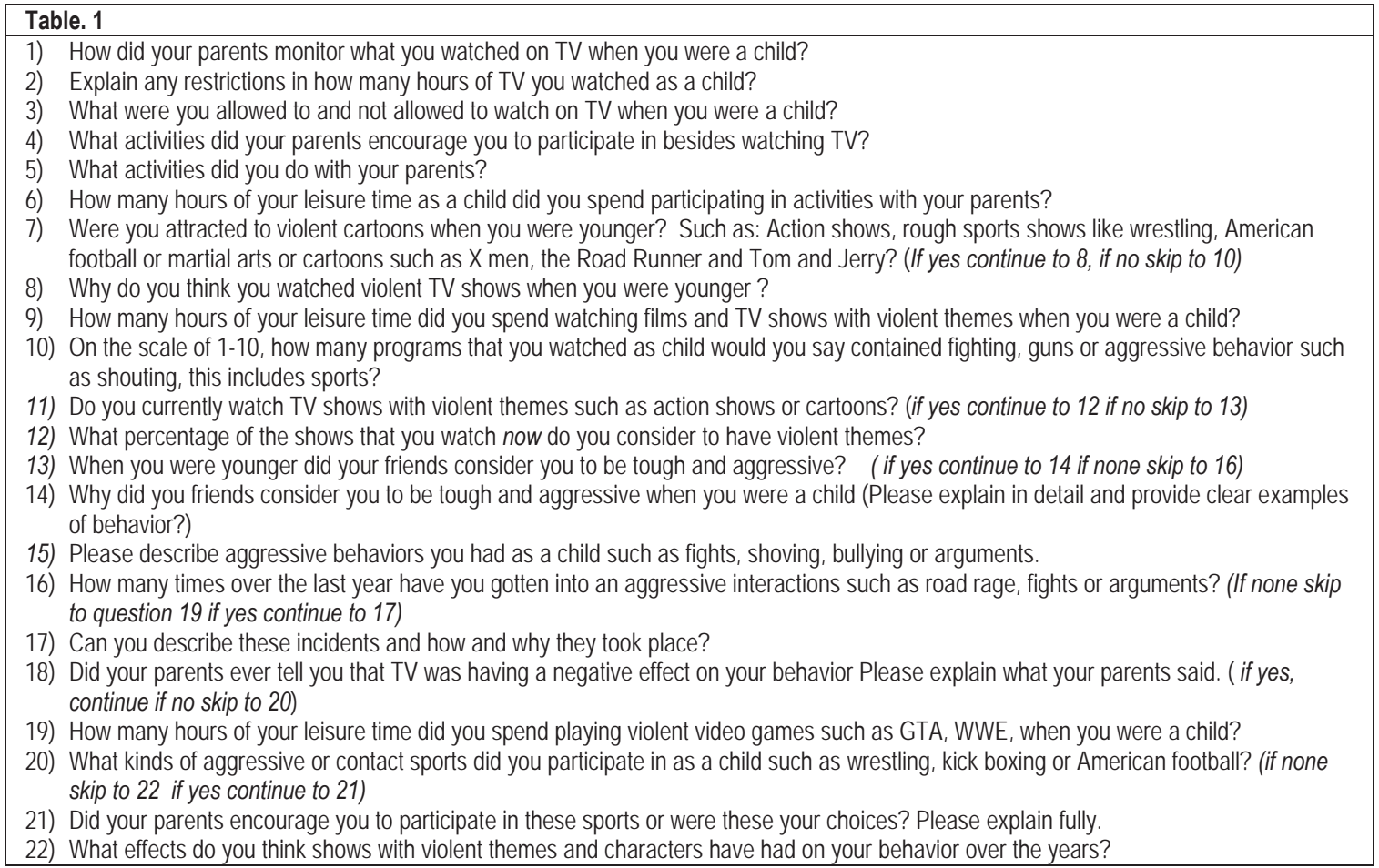

\section{Findings and Narratives}

After administering our survey to 120 subjects we are reporting the most significant findings. As part of our method, we wanted our participants to define violent behaviors themselves. Many respondents indicated that violent television had 
no effect on their behavior in numerous instances, and they failed to see that some behaviors were in fact violent acts. Case in point, some respondents, did not consider road rage as violent and perceived their aggressive behaviors and actions behind the wheel as justified, while others understood road rage as a clear act of aggression. One 18 year old subject said, "Over the years, I haven't gotten into aggressive interactions such as road rage, fights, or arguments," but at the same time he further asserted, "I think shows with violent themes and characters haven't had any effect on me since I didn't used to watch shows with violent themes." This demonstrates the lack of understanding with some respondents the correlation effect between violent content and violent behavior.

The respondents who reported parental mediation and control of their TV viewing had a greater understanding of violence but reported that often times it was only romantic and sexual themes that were censored by their parents. This mode of television mediation by parents is in line with Kuwait's censorship paradigm, where the Ministry of Information censors mainly romantic and sexual content on state own and run television channels. Inappropriate content is often deleted including kissing and intimate scenes. Conversely, violent shows are aired on TV uncensored in Kuwait and males are often allowed to watch these programs because they are associated with masculinity.

In our responses, clear contrasts were often seen with gender roles and aggression between males and females. Females seem to be more reserved and hesitant to share information that would label them as aggressive and males were more open to admitting their aggressiveness. Many females did not report having consumed any violent content as children and many said aggressive behaviors were acts they observed more in males and felt that violence on TV affected males more than it did themselves or other females: "Shows with violent themes have not affected my behavior, but it has impacted many other children especially the male gender," said a 30-year old female respondent.

Parents generally controlled what females watched on TV, while males were given more autonomy in this respect: "I was restricted from watching horror images or videos that could disturb my mentality or adult movies or videos. My parents would usually change the channel or fast forward it," one 21-year old female reported.

It was observed that parents of male respondents; however, were more likely to have given consent whether explicitly or tacitly for their male children to consume media violence since it is perceived as masculine. Males often played with toys that encouraged violence such as fake guns and swords. However, female respondents received negative reaction from parents if they viewed violent cartoons or engaged in aggressive playing. Females generally described being directed toward what was seen as more gender appropriate activities such as playing with dolls or watching programs that were more considered more suitable for young girls such as Disney cartoons, which lacked the violence of action shows and superhero cartoons that are often aimed at a male audience.

Many females were also directed toward participating in outside home activities more aligned with traditional gender roles: "I was pushed into swimming which I really loved... Also, drawing was something they perceived as a feminine activity that I could safely and easily waste my time doing," said a 21-year old female who reported her parents encouraged her to engage in activities aside from viewing TV that were imbued with stereotypical female attributes. Females recounting violent behavior were very low in our study but one female in our sample reported regular acts of violent behavior. She described herself as being the bully in the family who routinely beat up her younger brother and cousins. The 24-year old also correlates her TV viewing with her aggressive nature: "I think watching a lot of WWF (World Wrestling Federation), made me think I can fight and made me think as a child that I was able to fight like them, which made me excited and always wanting to wrestle with my friends and cousins."

While females are often discouraged from engaging in such aggressive behaviors and restricted from watching aggressive content, many times males reported that they were often encouraged to participate in physical and aggressive sports such as kick boxing, karate and soccer. Furthermore, the males in our sample were generally allowed to consume more violent TV programming than females. An 18 year old male respondent, for example, rated the amount of shows he watched that contained violent themes on a scale of 0-10. He described most of the shows he watched as an 8 for violent content. Another participant recalled playing out several violent scenes that he saw on TV without getting in trouble at home. However, when asked does he believe viewing media violence effects his behavior now as an adult, his answer was no. "I was a child then and now am an adult."

Nevertheless, some males did report that their parents took an interest in the content they were viewing on television and had strict rules and policies in place about what they could and couldn't watch. "My parents monitored me by sitting with me while I watched and showed me beneficial channels. They were aware of me and aware of what I am watching. For example, they even taught me how to pick up the main point from the beneficial channels and how to use the TV in a positive way because once I learned how to use it from the childhood, automatically I will know how to use it at this current age," said one 21-year old male respondent. Correspondingly, this subject further reported that he does not recollect exhibiting any aggressive tendencies as a child and his friends never considered him to be tough and aggressive. 
His story reflects our findings that there is a strong correlation between parental supervision and child aggression with less violence reported in households where parents actively engaged in mediation. The parental control methods reported were locking the channels, expressing verbally what sort of shows were inappropriate to watch, co-viewing and encouraging children to pursue other activities. "As a child, I think these shows had a small influence on my behavior. I used to be short tempered, and I believe that my interest in these shows and games had an effect on that. However, as I grew up, these influences faded away, though I still enjoy watching violent themed movies," said a 21-year old male. His parents generally discouraged violent TV viewing and even though he was a male and did watch some violent TV he said he tended to grow out of any aggressive influences TV seemed to have on him.

Several of the participants mentioned that their parents did not set guidelines or supervise what they consumed. Respondents who reported little or no parental supervision, also reported more exposure to violent content and exhibited such behaviors in many instances: "My friends used to consider me to be tough and aggressive because I was short tempered and could not take any offense; therefore would usually get into arguments and sometimes fights...I remember getting into a lot of arguments and rarely into fist fights," said a 24-year old male respondent who reported that his parents did not monitor what he watched on television when he was younger. Similar patterns were reported from a 21year old who consumed three hours of TV per day, many of which he said contained violent content: "My friends considered me aggressive and tough because I had aggressive tendencies. I was physically aggressive and I did things like punching. I also ordered people around...As a child, my aggressive behavior was physical like shoving, punching, and kicking." One 27-year old male, "Ali" (not his real name) recalled that his parents had strict rules on what he could consume when he was younger; however, he ranked the amount of shows that he watched that contained violence as 10 of out 10 . He also admits he consumed violent content on TV specifically because he wanted to be strong and to model the violent behaviors he observed. He said that he would imitate these characters and they made him want to fight.

Like Ali, 30-year old Ahmed (not his real name) also reported severe incidents of violence: "I was considered to be one of the toughest as a kid. I was a trouble maker and I would always end up in fights. I realize now because I was a tiny boy, I needed to prove myself within my peer circles. I would never miss out on a fight, and I would always stand up for my friends. As an example, when I was about 20, my little cousin, at the age of 14 , would always be bullied by the neighborhood kids because he had a smooth beautiful face and kids saw him as soft rather than a man. And one time he came home and his clothes were dirtied and he was a mess he had a frustrated face. He told me that some older guys were harassing him and I got angry. I went over to their house, found them around the neighborhood and straight on advanced aggressively, I pounded the first guy and kept pounding on him, me on top and him under me. The others reacted in trying to get me off, but I just continued what I was doing not seeing anything else. When a lot of people started to gather, I lifted him, pushed him through the crowd and into his house and that's when people starting fighting me back and I went home drenched in blood. There were many other incidents where I went home in blood and was driven to the emergency room more than I can count because of my aggressive behavior."

Despite these incidents, Ahmed however, said he didn't consider TV to have had an impact on his violent tendencies but still he recounted heavy TV viewing as child and that he was attracted to shows that contained violent themes and this continued into his adolescence: "Yes, what I watched majorly was violent shows, considering I am a male, and they included sport shows like wrestling and boxing, also many cartoon shows that depicted violence. As I grew, I started watching more and more TV shows that promoted violence too, like shows about soldiers or shows that showed the criminals of history."

Another male respondent, whose parents did monitor what he watched on TV, felt that TV still had an effect on him but in a positive light: "I believe these shows (violent shows) have educated me on the consequences associated with violent behavior. I also believe that I personally benefitted from these shows because they represented part of a wide spectrum of television shows with varying themes in which I was giving insight into the mechanics of the world," the 18year old said.

In contrast to Ali and Ahmed, a few male respondents reported very little parental supervision but also noted they did not feel the pressure to watch violent shows and did not necessarily gravitate toward violent content on TV. However, these males, like Ali and Ahmed, found that the violent content they consumed did have an impact on how they exhibited violence in their adolescent stage: "I didn't used to watch violent things when I was a kid but still when I grew up I found it necessary to defend myself and my family and my friends and I started to act aggressively when needed. So I used violent aggressive shows as a way to solve problems later," reported an 18-year old male.

In some cases the respondents in our sample described that they felt TV had contributed to negative behaviors but not necessarily violent ones and some note that their parents had pointed out these detrimental habits, and this was especially true with our female respondents: "Yes, my parents told me that TV was having a negative effect on my behavior because it was distracting me from my studies and was making me lazy," a female reported. Another female, 
25, also reported negative behaviors that were not necessarily violent but felt were the result of the modeling behaviors from TV: "Violence was never a focus in the TV shows I would watch. However, in general when I saw a way a character handled a situation, it might have encouraged me to act the same way, and I would even go as much as saying that I thought it was acceptable. For example, if a kid was cheating and decided to write answers on his shoes, I might have been encouraged to try such method and see where it takes me."

While the vast majority of our respondents, even the ones with high levels of violent TV consumption and violent behavior, did not blame this on the influence of TV, there were a few participants who highlighted TV as the primary agent that influenced their violent behaviors. But almost all the these respondents also said that while TV made them more violent, that was not necessarily bad, as they are more able to defend themselves, and in many cases their families. This was especially reported among the male respondents, with one 22-year old male explaining, "It (TV) affected me both negatively and positively. Negatively because I 've become a somewhat aggressive person and positively because now I'm strong enough to look out for myself and be brave." Yet another 22- year old male subject reported being unashamed or even proud of his violent demeanor, he described regular acts of violence at school when he was younger, which included being the class bully along with his friends. The group of boys would pick on other kids and beat on each other and often times he ended up being suspended from school. He readily admits that TV was a major influence on his behavior but he doesn't regret that influence and asserts that TV "has made me the man I am today."

\section{Conclusion}

In our study we noticed several trends across our interviews: There were stark differences between males and females and how they assimilated and modeled violent behaviors seen on television. Males were often allowed to consume violent content because this is recognized as more masculine while females were often discouraged from watching violent content as culturally this are seen as a inappropriate for young girls. Males who watched large amounts of TV often engaged in violent acts but did not interpret this behavior as being influenced by TV viewing. It is assumed that this denial could be cultural socialization where it's better to be influenced by parents and friends than by an external influence that is not inherent in the society. Men in Kuwait are socialized to be strong and admitting to the influence of television may be perceived as a sign of weakness since TV is dominated by western programming and not traditional Arab or Kuwaiti values. However, the males that did admit to the violent influence of TV utilized the collectivist culture to justify their aggression saying they needed to defend their families, which is a fundamental role for males in Kuwait. Moreover, we noticed females more likely to model deviant behaviors such as cheating or neglecting their studies and being lazy. These are traits often are acceptable for females in this society to exhibit. When parental mediation was present, respondents reported less violent modeling as they were able to reconcile fact from fiction and understand the consequences of aggressive behaviors.

\section{References}

Anderson, C. A., Berkowitz, L., Donnerstein, E., Huesmann, L. R., Johnson, J. D., Linz, D., \& Wartella, E. (2003). The influence of media violence on youth. Psychological science in the public interest, 4(3), 81-110.

Bandura, A., Ross, D., \& Ross, S. A. (1961). Transmission of aggression through imitation of aggressive models. The Journal of Abnormal and Social Psychology, 63(3), 575.

Bandura, A., \& Walters, R. H. (1963). Social learning and personality development.

BBC.com. (May 2013) Kuwait Profile. Retrieved June 15 from http://www.bbc.com/news/world-middle-east-14646837

Black, D., Newman, M., (1995) Television Violence and Children: Its Effects Need To Be Seen In The Context of Other Influences on Children's Mental Health. BMJ: British Medical Journal, Vol. 310, No. 6975), pp. 273-274

Davies, J. J., \& Gentile, D. A. (2012). Responses to children's media use in families with and without siblings: A family development perspective. Family Relations, 61(3), 410-425.

Dominick, Joseph, R (2009). The Dynamics of Mass Communication: Media in the Digital Age.

New York, NY: McGraw-Hill

Eron, L. E. (1982). Parent-child interaction, television violence, and aggression of children. American Psychologist, 37(2), $197-211$.

Gentile, D. A., Nathanson, A. I., Rasmussen, E. E., Reimer, R. A., \& Walsh, D. A. (2012). Do you see what I see? Parent and child reports of parental monitoring of media. Family Relations, 61, 470-487.

Hagen, I. (2007). We can't just sit the whole day watching TV': Negotiations concerning media use among youngsters and their parents. Young, 15(4), 369-393.

Hajeeh, M., \& Lairi, S. (2009). Marriage partner selection in Kuwait: An analytical hierarchy process approach. Journal of Mathematical Sociology, 33(3), 222-240.

Hicks, D. J. (1968). Effects of co-observer's sanctions and adult presence on imitative aggression. Child Development, 39(1), 303-309. 
Hopf, W. H., Huber, G. L., \& Weiß, R. H. (2008). Media violence and youth violence: A 2-year longitudinal study. Journal of Media Psychology: Theories, Methods, and Applications, 20(3), 79- 96.

Huesmann, R. L., Lagerspetz, K., \& Eron, L. D. (1984). Intervening variables in the TV violence-aggression relation: Evidence from two countries . Developmental Psychology, 20(5), 746-775.

Kirmayer, L., Lemelson, R., \& Barad, M. (2007) Understanding Trauma: Integrating Biological, Clinical, and Cultural Perspectives. New York: Cambridge University Press.

Krcmar, M., \& Vieira, Jr., E. T. (2005). Imitating life, imitating television: The effects of family and television models on children's moral reasoning. Communication Research, 32(3), 267-294.

Martins, N., \& Harrison, K. (2012). Racial and gender differences in the relationship between children's television use and self-esteem: a longitudinal panel study. Communication Research, 39(3), 338-357.

Mitchell, C., Dinkha, A., Kononova, A., Rashwan, T., Matta, M., (2014). A Body of Dissatisfaction: A Study of the Effects of Media Imperialism in Kuwait, American Journal of Humanities and Social Sciences, Vo1. 2, No. 1, 2014, 76-87

Murray, J. P. (2008). Media violence the effects are both real and strong. American Behavioral Scientist, 51(8), 1212-1230.

Myers, D. (2012). Social Relations. Social Psychology (ED 10). McGraw Hill.

Reporters Without Borders, World Press Freedom Index - 2013, (2013) retrieved from: http://www.refworld.org/docid/5108f621e.html, retrieved, 28 June 2014

Shah, N. M., Badr, H. E., Yount, K., \& Shah, M. A. (2011). Decline in co-residence of parents and children among older Kuwaiti men and women: What are the significant correlates?. Cross Cultural Geronotology, 26(2), 157-174.

Von Feilitizen,C (1976). The functions served by the mass media. In R .Brown (Ed.), Children and television ( pp. 90-115) London. Collier-Macmillan.

Walsh, A. D., Laczniak, R. N., \& Carlson, L. (1998). Mothers' preferences for regulating children's television. 27(3), 23-36.

Werner, Sonia Soneson,. Affect and Moral Judgment in Older Children. Thesis. N.d. N.p.: n.p., 1979. Print.

Wheeler, D. (2000). New media, globalization, and Kuwaiti national identity. Middle East Journal, 54(3), 432-444. 